\title{
Aa. Vv., Il romanzo francese del Novecento, a cura di Sandra Teroni
}

Stefano Genetti

\section{(2) OpenEdition}

1 Journals

\section{Edizione digitale}

URL: http://journals.openedition.org/studifrancesi/8078

DOI: $10.4000 /$ studifrancesi.8078

ISSN: 2421-5856

\section{Editore}

Rosenberg \& Sellier

\section{Edizione cartacea}

Data di pubblicazione: 1 juillet 2009

Paginazione: 441-442

ISSN: 0039-2944

\section{Notizia bibliografica digitale}

Stefano Genetti, «Aa. Vv., I/ romanzo francese del Novecento, a cura di Sandra Teroni», Studi Francesi [Online], 158 (LIII | II) | 2009, online dal 30 novembre 2015, consultato il 07 janvier 2021. URL: http:// journals.openedition.org/studifrancesi/8078; DOI: https://doi.org/ERREUR PDO dans /localdata/ www-bin/Core/Core/Db/Db.class.php L.34 : SQLSTATE[HY000] [2006] MySQL server has gone away

Questo documento è stato generato automaticamente il 7 janvier 2021.

\section{(c) (i) $\odot$}

Studi Francesi è distribuita con Licenza Creative Commons Attribuzione - Non commerciale - Non opere derivate 4.0 Internazionale. 


\title{
Aa. Vv., Il romanzo francese del Novecento, a cura di Sandra Teroni
}

\author{
Stefano Genetti
}

\section{NOTIZIA}

HÉLÈNE DE JACQUELOT - ANNE MARIE JATON - ANNAMARIA LASERRA - FLAVIA MARIOTTI - SANDRA

TERONI, Il romanzo francese del Novecento, a cura di Sandra TERONI, Roma- Bari, Laterza, 2008 («Manuali Laterza», 263), pp. 153.

1 È questo il primo volume di argomento novecentesco a essere pubblicato nella serie «Istituzioni di letteratura francese» diretta da Francesco Fiorentino, una più che opportuna iniziativa editoriale che fornisce messe a punto critiche e strumenti didattici adatti ai riformati programmi universitari. Corredato, oltre che di indice dei nomi, di Riferimenti bibliografici essenziali e di una Tavola cronologica che coordina avvenimenti storici e artistico-culturali, romanzi francesi e stranieri, il libro traccia un panorama incisivo e variegato, necessariamente sintetico e selettivo ma mai enumerativo, che da Proust arriva a Perec e al quale si affiancherà prossimamente, nella stessa collana, Il romanzo francese contemporaneo, a cura di Gianfranco Rubino.

2 Strutturata in tre capitoli, la trattazione segue un ordine cronologico duttile, che prevede collegamenti interni - da Gide al nouveau roman, da Roussel all'OuLiPo - e richiami ai medesimi autori in contesti diversi: se di Au château d'Argol di Julien Gracq si parla ad esempio in margine al Surrealismo, su Le Rivage des Syrtes e Un balcon en forêt si torna in merito alle meditazioni sulla guerra. Spesso inquadrati da osservazioni riguardanti l'impatto degli eventi storici e delle situazioni politico-economiche sul divenire della narrativa, i paragrafi si succedono agili e densi. Pur riprendendo etichette canoniche quali romanzo dell'adolescenza, récit poétique o roman-fleuve, si evitano annessioni ideologiche o estetiche tanto collaudate quanto approssimative: non si cerca cioè l'omogeneità ad ogni costo, evidenziando anche ricerche più o meno isolate come quelle di Bataille, Cohen o Simon. Le autrici non solo dedicano un 
capitoletto alla littérature concentrationnaire e trovano spazio per accennare al poliziesco come modello di sperimentazione narrativa, ma una sezione, a firma della curatrice, concerne la metaforizzazione del viaggio e la decostruzione dell'esotismo e del cosmopolitismo, dell'ansia di evasione e di alterità, negli eterogenei racconti, tra gli altri, di Morand, Nizan, Michaux, Leiris e Artaud, libri del disincanto che contaminano reportage e finzione, diaristica e saggistica e dove «la deriva del viaggio in fuga e in erranza si esprime come crisi di raffigurabilità del mondo stesso» (p. 39). A rafforzare una visione del romanzo come epicentro della riflessione sul fatto letterario contribuiscono i cenni al ruolo svolto dalle riviste e un'attenzione particolare è riservata ai momenti in cui il romanzo sovverte se stesso, esplorando al contempo le proprie potenzialità: dal récit surrealista alla smaterializzazione del tessuto narrativo $\mathrm{e}$ alla disidentificazione della voce operata da Blanchot, Bousquet, des Forêts o Beckett. L'evoluzione delle forme narrative viene costantemente inserita nel dibattito teorico che la alimenta, sottolineando così, tra avaguardismi e smantellamento delle mitologie del moderno, tra dissoluzione della storia e ritorno alla Storia, la specificità metanarrativa e autoriflessiva di molto romanzo novecentesco. 